\title{
Theory of mind in users of anabolic androgenic steroids
}

\author{
Anja Vaskinn $^{1,2}$ (D) $\cdot$ Lisa E. Hauger ${ }^{3} \cdot$ Astrid Bjørnebekk $^{3}$
}

Received: 3 April 2020 / Accepted: 26 June 2020 / Published online: 5 July 2020

(C) The Author(s) 2020

\begin{abstract}
Rationale Anabolic androgenic steroids are used to improve physical performance or increase lean muscle mass. About one-third of users develop a dependency syndrome, which is characterized by elevated rates of psychopathology, cognitive impairments, and aggressive and antisocial behaviors. The mechanisms behind these intra- and interpersonal problems are not known.

Objective To examine theory of mind (ToM), i.e., the ability to infer the mental state of others, in users of anabolic androgenic steroids. Reduced ToM may be one factor underlying the interpersonal problems that have been reported with prolonged use of anabolic androgenic steroids.

Methods The Movie for the Assessment of Social Cognition (MASC) was used to assess ToM. Study participants were male/ female weightlifters who used anabolic androgenic steroids (AAS, $n=34 / 9$ ), who were dependent on anabolic androgenic steroids (AASdep, $n=44 / 7$ ), and a non-using weightlifting comparison group (WLC, $n=69 / 16$ ).

Results Analyses of variance showed that the AASdep group performed significantly worse than the WLC group, for all MASC measures (total ToM, cognitive ToM, affective ToM, overmentalizing/undermentalizing errors). Sex and sex x group interaction effects were non-significant.

Conclusions Male and female weightlifters who were dependent on anabolic androgenic steroids had impaired ToM. Their reduced social cognition may be one contributing factor to the elevated rates of antisocial behavior reported in this population.
\end{abstract}

Keywords Mentalizing $\cdot$ Mindreading $\cdot$ Testosterone $\cdot$ Dependence $\cdot$ Social cognition

\section{Introduction}

Human social behavior is a result of numerous interacting factors. Among these are the "social" hormones oxytocin and testosterone. Whereas oxytocin, aka the "love" hormone in popularized jargon, is involved in affiliative behavior, bonding, and care (Macdonald and Macdonald 2010), testosterone has often been linked to aggression (Montoya et al. 2012). The complete picture, however, is

Anja Vaskinn

anja.vaskinn@medisin.uio.no

1 Norwegian Centre for Mental Disorders Research, Division Mental Health and Addiction, Oslo University Hospital, PO Box 4956, Nydalen, 0424 Oslo, Norway

2 Institute of Clinical Medicine, University of Oslo, PO Box 1171, Blindern, 0318 Oslo, Norway

3 The Anabolic Androgenic Steroid Research Group, National Advisory Unit on Substance Use Disorder Treatment, Division Mental Health and Addiction, Oslo University Hospital, PO Box 4959, Nydalen, 0424 Oslo, Norway less straightforward. Although both hormones influence human social behavior, the effect depends on the situation (van Honk et al. 2011a). Oxytocin can have antisocial effects, if antisociality provides benefits for offspring, ingroup members, or reproductive partners (Beery 2015). Testosterone has been proposed to drive motivation for seeking and maintaining social status, and not for aggression per se (Eisenegger et al. 2011). Interestingly, single dose administration of testosterone has been shown to lead to suppression of facial mimicry (Hermans et al. 2006), reduced ability to infer the emotions and intentions of others (Van Honk et al. 2011b), and to reduced trust (Bos et al. 2010). When competing for social status, there may be clear disadvantages to trusting, caring, or empathizing with the rival (Eisenegger et al. 2011). The reduced social cognition seen in these studies may therefore be beneficial for the individual in the situation where (s)he seeks social status. However, reduced social cognition also has clear disadvantages. Understanding and empathizing with the feelings of another is a key ingredient of mutually satisfying relationships. Indeed, social cognitive impairment is an important predictor of reduced social functioning in 
various mental disorders (Fett et al. 2011; Vlad et al. 2018; Halversen et al. 2019), including substance use disorders (Preller et al. 2014).

Administration of testosterone-like substances far beyond a single dose is at the core of one substance use disorder, namely anabolic steroid dependence. Anabolic androgenic steroids (AAS) comprise testosterone and its synthetic derivatives. Due to their anabolic effect, they are used by athletes, bodybuilders, and recreational athletes, to improve physical performance or increase lean muscle mass. Moreover, due to profound masculinizing features of AAS, they are foremost used by men (Sagoe et al. 2014), although use is also seen among female bodybuilders or fitness athletes (Gruber and Pope Jr 2000). When used to increase muscle mass (Parkinson and Evans 2006), they are often administered in doses that exceed the natural male production by 5-100 times (Brower 2002). These supraphysiological doses cause large alterations to the hormonal system, which in turn likely increase the hormonal effects on cognition, mood, and behavior.

It is estimated that about a third of AAS users develop a dependency syndrome, characterized by a maladaptive pattern of AAS use, which is maintained despite substantial negative consequences (Brower 2002; Kanayama et al. 2009a). Among adverse side effects reported for prolonged AAS use are reduced social (Hauger et al. 2019) and non-social cognition (Kanayama et al. 2013; Heffernan et al. 2015; Bjørnebekk et al. 2019; Hauger et al. 2020), increased psychiatric symptoms (Kanayama et al. 2008; Oberlander and Henderson 2012), and medical problems (Oskui et al. 2013), including damage to the cardiovascular system (Kanayama et al. 2008; Far et al. 2012; Baggish et al. 2017; Rasmussen et al. 2018) and infertility (de Souza and Hallak 2011). AAS users who develop a dependency syndrome report elevated rates of psychopathology (Kanayama et al. 2009b), psychological distress, and executive dysfunction (Hauger et al. 2020) compared with non-dependent AAS users. Furthermore, AAS dependence is associated with higher levels of involvement in aggressive and antisocial behaviors (Copeland et al. 1998, 2000). The exact mechanisms behind these elevated rates in dependent AAS users are unknown. Administration of testosterone has been shown to increase aggression (Montoya et al. 2012), which is one of the side effects that are commonly linked to AAS use (Beaver et al. 2008; Pope Jr and Katz 1994; Yates et al. 1992). However, these are complex relationships, probably including a number of mediating factors. It is quite possible that the negative outcomes seen in prolonged use/dependency of AAS are attributable to premorbid factors responsible for both the dependency and increased interpersonal problems.

AAS have, as testosterone, been associated with socialemotional processes. We have previously shown that AAS dependence is associated with impaired social cognition, more specifically the ability to recognize emotions in moving bodies (Hauger et al. 2019). One definition of social cognition refers to it as the "mental operations that underlie social interactions, including perceiving, interpreting and generating responses to the intentions, dispositions and behavior of others" (Green et al. 2008). This is a wide definition, and the ability to recognize emotions displayed by others, or emotion perception, is one of several social cognitive domains (Pinkham 2014). In our previous study, emotion perception was assessed using basic point-light stimuli (Hauger et al. 2019). This social cognitive process entails decoding human movement in simple stimuli and can be considered a bottom-up process (Ochsner 2008). Another social cognitive domain, mentalizing/theory of mind (ToM), on the other hand, is a top-down deductive process (Ochsner 2008), involving the capacity to infer and interpret the mental state of others (Brüne and Brüne-Cohrs 2006). To our knowledge, ToM has thus far not been investigated in AAS users. Given studies that have found ToM impairments in other substance using populations (Bora and Zorlu 2017; Sanvicente-Vieira et al. 2017), one might suspect that it may be reduced also in AAS dependence. Support for such a hypothesis also comes from research in developmental psychology suggesting that androgens may influence on ToM. One study found that fetal testosterone levels had an impact on empathy in 6-8 year olds (Chapman et al. 2006). This finding was corroborated in more recent work, where it was shown that the level of prenatal androgens could exert an influence on ToM (Khorashad et al. 2018). One speculation is that impaired ToM could be one mechanism behind the elevated rates of interpersonal problems in AAS dependence (Copeland et al. 1998, 2000). In this study, we examine ToM in users of AAS, with or without dependence, compared with weightlifting control participants. We hypothesize reduced ToM performance in AAS users with dependence.

\section{Methods}

\section{Participants}

Study participants consisted of male $(n=147)$ and female $(n=32)$ weightlifters $>18$ years of age with either (a) current or previous use of AAS or (b) no previous or current use of AAS or other doping substances. Participants were recruited via social media (Facebook) and online forums and webpages targeting people interested in heavy weight-training or bodybuilding. Additionally, posters and flyers were distributed in selected gyms in Oslo, Norway, and some recruitment took place through snowball sampling. Prior to participation, all participants received a brochure with a description of the study, and written informed consent was collected. The study was conducted in accordance with the Declaration of Helsinki and received ethical approval from the Regional Committee 
for Medical and Health Research Ethics in South-Eastern Norway (2013/601). Participants received NOK $1.000(\approx$ $\$ 125)$ as compensation for taking part in the study.

Exclusion criteria were a history of severe head injury with loss of consciousness for $>1 \mathrm{~min}$, a neurological disorder (e.g., history of diagnosed stroke, brain tumor, Parkinson's disease, or epilepsy), or IQ $<80$. We were interested in AAS use across biological sex. As AAS are used almost exclusively by males $(98 \%)$, different inclusion criteria were applied for the two sexes in order to secure the inclusion of females. Male AAS users were included if they had $>1$ year of cumulative AAS exposure, when summarizing periods on cycle. Female AAS users were included if they had used AAS for at least one cycle. In total, 192 participants (159 males/33 females) were eligible for participation and enrollment in the overall study (Bjørnebekk et al. 2019), but 5 did not meet the inclusion criteria. In addition, 8 participants were not included in the current study due to missing data for the main study variable. The male sample is largely overlapping with the one described in our previous work which included only males (Hauger et al. 2019, 2020; Bjørnebekk et al. 2019). Three groups of weightlifters participated. The weightlifting control participant group (WLC) consisted of 85 individuals (69 males/16 females). There were 43 individuals in the non-dependent AAS group (AASnondep) (34 males/9 females). The dependent AAS group (AASdep) had 51 participants (44 males/7 females). The subdivision into AASdep and AASnondep was based upon AAS dependence criteria (Kanayama et al. 2009c). These are described in the next section.

Sex differences appeared, unsurprisingly, for weight and height, in the expected direction (males $>$ females). Furthermore, the three groups differed significantly for length of education and IQ. The AASdep group had the shortest education and the lowest IQ. Significant group differences were also present for drug use, with AAS dependent males showing particularly elevated scored (one standard deviation above the normative mean). For details concerning demographics and alcohol/drug use, see Table 1.

\section{Clinical measures}

The presence of lifetime AAS dependence was evaluated in a standardized clinical interview using a version of the Structured Clinical Interview for DSM-IV (SCID) (First et al. 1996). This version is based upon the standard substance-dependence criteria of DSM-IV, but has been modified and adapted to apply specifically to AAS dependence (Kanayama et al. 2009c), preserving adequate psychometric properties (Pope et al. 2010). AAS dependence was considered to be present if participants had a maladaptive pattern of AAS use causing clinically significant impairment or distress, manifested by three (or more) of the DSM-IV criteria (Kanayama et al. 2009c) reported in the same 12-month period. The AASdep group included users with a lifetime history of AAS dependence, both current and previous. The two substance use scales of the Achenbach System of Empirically Based Assessment (ASEBA) and Adult SelfReport (ASR) questionnaire (Achenbach and Rescorla 2003) were used to provide measures of use of illegal drugs during the past 6 months. There was some missing data for males (WLC: 5, AAS: 6, AASdep: 8-9). Significant group differences appeared for the drug use subscale, with the AASdep showing the highest rates, see Table 1 for details. Characteristics related to use of AAS in the two AAS groups are shown in Table 2 .

Relevant background information was captured by a semistructured interview. The interview also covered details about AAS use, such as age of onset, administration patterns, years of use, weekly dosage, and experienced side effects. The AASdep group had used AAS for a longer time and reported significantly more physical, psychological, and cognitive side effects than the AAS group.

\section{Cognitive measures}

IQ was assessed with the short version of the Wechsler Abbreviated Scale of Intelligence (WASI) (Wechsler 2007) which is comprised of the Vocabulary and Matrix Reasoning subtests. ToM was assessed with the Norwegian version (Fretland et al. 2015) of the Movie for the Assessment of Social Cognition (MASC) test (Dziobek et al. 2006). It is a 15-min movie depicting four characters in real-life interactions. The movie is paused 45 times and the test-taker instructed to answer questions concerning a character's thoughts, emotions, or intentions. MASC is an ecologically valid test that provides not only an overall ToM score (MASCtot) but also information on cognitive (MASCcog) and affective (MASCaff) ToM. We categorized items as cognitive (thoughts, intentions) or affective (emotions) in accordance with previous research using the Norwegian version (Vaskinn et al. 2018). Furthermore, the test yields information on a person's mentalizing style through its multiple choice response format. Every item has four response options. In addition to the correct answer, the response options correspond to overmentalizing (excessive attribution of mental state: MASCexc), undermentalizing (underinterpretation of mental state: MASCless), and no mentalizing (no attribution to mental state: MASCno).

\section{Statistical analyses}

The overall research aim concerning group and sex differences in ToM performance was examined with a univariate analysis of variance (ANOVA) where MASCtot was entered as the dependent variable. Subsequently, two repeated measures ANOVAs (or mixed within-between-subjects 
Table 1 Demographics of individuals using anabolic androgenic steroids (AAS), individuals with anabolic androgenic steroid dependence (AASdep), and of weightlifting control participants (WLC)

\begin{tabular}{|c|c|c|c|c|c|c|c|}
\hline & \multicolumn{2}{|c|}{ WLC $(n=85)$} & \multicolumn{2}{|c|}{$\operatorname{AAS}(n=43)$} & \multicolumn{2}{|c|}{ AASdep $(n=51)$} & \multirow[t]{2}{*}{ Statistics } \\
\hline & $\begin{array}{l}\text { Females } \\
n=16 \\
\text { Mean (SD) }\end{array}$ & $\begin{array}{l}\text { Males } \\
n=69 \\
\text { Mean (SD) }\end{array}$ & $\begin{array}{l}\text { Females } \\
n=9 \\
\text { Mean (SD) }\end{array}$ & $\begin{array}{l}\text { Males } \\
n=34 \\
\text { Mean (SD) }\end{array}$ & $\begin{array}{l}\text { Females } \\
n=7 \\
\text { Mean (SD) }\end{array}$ & $\begin{array}{l}\text { Males } \\
n=44 \\
\text { Mean (SD) }\end{array}$ & \\
\hline Age & $28.4(4.5)$ & $31.8(9.5)$ & $28.7(7.5)$ & $33.2(8.3)$ & $34.0(7.4)$ & $33.4(8.6)$ & $\begin{array}{l}\text { Group: } F=1.5, p=0.229 \\
\text { Sex: } F=1.9, p=0.169 \\
\text { Gx S: } F=0.6, p=0.528\end{array}$ \\
\hline Education & $16.0(2.1)$ & $15.8(2.7)$ & $14.6(1.5)$ & $14.5(2.7)$ & $14.2(2.7)$ & $13.9(2.2)$ & $\begin{array}{l}\text { Group: } F=5.5, p=0.005 \\
\text { Sex: } F=0.1, p=0.707 \\
\text { Gx S: } F=0.0, p=0.979\end{array}$ \\
\hline WASI IQ & $108.0(8.1)$ & $113.0(9.4)$ & $101.0(16.2)$ & $107.8(11.5)$ & $102.7(15.2)$ & $102.6(11.5)$ & $\begin{array}{l}\text { Group: } F=5.4, p=0.005 \\
\text { Sex: } F=3.0, p=0.085 \\
\text { Gx S: } F=0.7, p=0.495\end{array}$ \\
\hline Height $(\mathrm{cm})$ & $167.2(7.8)$ & $180.7(6.9)$ & $165.4(6.5)$ & $179.7(6.1)$ & $167.7(6.8)$ & $181.3(7.7)$ & $\begin{array}{l}\text { Group: } F=0.6, p=0.556 \\
\text { Sex: } F=90.4, p<0.001 \\
\text { Gx S: } F<0.1, p=0.970\end{array}$ \\
\hline Weight (kg) & $65.5(9.8)$ & $90.5(14.0)$ & $64.3(9.8)$ & $94.1(12.9)$ & $68.0(10.2)$ & $99.2(13.9)$ & $\begin{array}{l}\text { Group: } F=1.5, p=0.222 \\
\text { Sex: } F=112.1, p<0.001 \\
\text { Gx S: } F=0.6, p=0.563\end{array}$ \\
\hline \multicolumn{8}{|l|}{ Activity, $n(\%)$} \\
\hline Body building & $7(44 \%)$ & $6(9 \%)$ & $2(22 \%)$ & $9(26 \%)$ & $3(43 \%)$ & $14(32 \%)$ & Group $x$ activity: \\
\hline Weightlifting & $2(13 \%)$ & $18(26 \%)$ & $0(0 \%)$ & $1(3 \%)$ & $1(14 \%)$ & $0(0 \%)$ & $x^{2}=23.7, p=0.003$ \\
\hline Combat & $1(6 \%)$ & $4(6 \%)$ & $2(22 \%)$ & $4(12 \%)$ & $0(0 \%)$ & $5(11 \%)$ & Sex x activity: \\
\hline Recreational & $5(31 \%)$ & $31(45 \%)$ & $5(56 \%)$ & $15(44 \%)$ & $3(43 \%)$ & $20(46 \%)$ & $x^{2}=6.2, p=0.182$ \\
\hline Other & $1(6 \%)$ & $9(13 \%)^{1}$ & $0(0 \%)$ & $5(15 \%)$ & $0(0 \%)$ & $5(11 \%)$ & \\
\hline Alcohol use T & $55.9(5.3)$ & $60.0(7.0)^{2}$ & $58.1(4.4)$ & $56.6(7.0)^{3}$ & $58.0(7.5)$ & $57.7(7.1)^{4}$ & $\begin{array}{l}\text { Group: } F=0.1, p=0.922 \\
\text { Sex: } F=0.3, p=0.602 \\
\text { Gx S: } F=1.8, p=0.164\end{array}$ \\
\hline Drug use $\mathrm{T}$ & $50.3(1.3)$ & $51.6(6.8)^{2}$ & $52.9(5.4)$ & $54.4(8.6)^{3}$ & $54.9(8.3)$ & $60.1(15.2)^{5}$ & $\begin{array}{l}\text { Group: } F=3.9, p=0.023 \\
\text { Sex: } F=1.8, p=0.181 \\
\text { Gx S: } F=0.4, p=0.690\end{array}$ \\
\hline
\end{tabular}

Entries in italics means that a result is statistically significant

${ }^{1}$ One male in the weightlifting group had missing value for this variable

${ }^{2} n=62$ due to missing data

${ }^{3} n=28$ due to missing data

${ }^{4} n=36$ due to missing data

${ }^{5} n=37$ due to missing data

Table 2 Characteristics related to use of AAS of the non-dependent (AAS) and dependent (AASdep) subgroups

\begin{tabular}{lllll}
\hline & $\begin{array}{l}\text { AAS } \\
(n=43)\end{array}$ & $\begin{array}{l}\text { AASdep } \\
(n=51)\end{array}$ & \multicolumn{2}{l}{ Statistics } \\
\hline & Mean (SD) & Mean (SD) & $t$ & $p$ value \\
Debut age of AAS use & $23.3(5.8)$ & $21.6(7.0)$ & 1.25 & 0.214 \\
Total years of AAS use & $6.5(5.4)$ & $10.0(6.1)$ & 2.9 & 0.043 \\
Estimated weekly AAS dose & $1059.5(1275.6)^{1}$ & $1287.2(864.4)^{2}$ & 0.99 & 0.322 \\
& $n(\%)$ & $n(\%)$ & $X^{2}$ & $p$ value \\
Current AAS use & $27(62.8)$ & $32(62.8 \%)$ & 0.00 & 0.996 \\
Physical side effects & $33(76.8 \%)$ & $48(94.1 \%)$ & 5.91 & 0.015 \\
Psychological side effects & $26(60.5 \%)$ & $46(90.2 \%)$ & 11.50 & 0.001 \\
Cognitive side effects & $11(25.6 \%)$ & $31(60.8 \%)$ & 11.70 & 0.001 \\
\hline
\end{tabular}

${ }^{1} n=38$ due to missing data

${ }^{2} n=50$ due to missing data 
ANOVAs) were conducted, for type of ToM (cognitive versus affective ToM) or ToM error types (overmentalizing, undermentalizing, or no mentalizing errors), respectively. In the first, a $2 \times 3 \times 2$ repeated measures ANOVA, sex (males/ females), and group (WLC, AAS, AASdep) were entered as between-subjects factors and the two MASC subscales (MASCcog, MASCaff) as within-subject factor. The second was a $2 \times 3 \times 3$ repeated measures ANOVA where the only difference from the former was the entering of the three MASC error scores (MASCexc, MASCless, MASCno) as within-subject factor.

We conducted two types of follow-up analyses for MASCtot. First, background variables for which statistically significant differences appeared in initial group comparisons, i.e., IQ and drug use, (Table 1) were entered as covariates in separate follow-up analyses. Since education can be considered a proxy for IQ, it was not examined further. Second, possible differences between AAS users on and off cycle were examined through a univariate ANOVA with group (AAS versus AASdep) and cycle (on versus off) as independent variables. All analyses were conducted using The Statistical Package for the Social Sciences (IBM SPSS Statistics for Windows, Version 26.0, IBM Corp, Armonk, NY).

\section{Results}

The overall univariate ANOVA yielded a significant main effect of group on MASCtot $\left[F_{(5,179)}=5.63, p=0.004, \eta=\right.$ 0.06]. Post hoc Scheffe tests indicated that the WLC and AASdep groups differed significantly $(p=0.02)$. The main effect of $\operatorname{sex}\left[F_{(5,179)}=0.04, p=0.839, \eta=0.00\right]$ and the group $\mathrm{x}$ sex interaction effect $\left[F_{(5,179)}=0.85, p=0.430, \eta=\right.$ $0.01]$ were non-significant. In the repeated measures ANOVA for ToM type, the main between-subject effect of group was significant $\left[F_{(2,173)}=5.19, p=0.007, \eta=0.06\right]$. Again, it was the WLC and AASdep groups that differed significantly (post hoc Scheffe, $p=0.002)$. Both the main effect of $\operatorname{sex}\left[F_{(2,173)}=\right.$ $0.21, p=0.645, \eta=0.00]$ and the group $\mathrm{x}$ sex interaction $\left[F_{(2,173)}=0.62, p=0.538, \eta=0.00\right]$ effect were non-significant. The main within-subject effect of ToM type was significant $\left[F_{(1,173)}=730.48\right.$, Wilk's Lambda $=0.19, p<0.001, \eta=$ 0.81 ] (see Fig. 1).

In the repeated measures ANOVA for ToM errors, the main between-subject effect of group was significant $\left[F_{(2,173)}=5.50, p=0.005, \eta=0.06\right]$, with post hoc Scheffe test showing again that the significant difference was between WLC and AASdep groups. Also again, both the main effect of $\operatorname{sex}\left[F_{(2,173)}=0.09, p=0.762, \eta=0.00\right]$ and the group $\mathrm{x}$ sex interaction $\left[F_{(2,173)}=0.76, p=0.470, \eta=0.00\right]$ effect were non-significant. The main within-subject effect of ToM error was significant $\left[F_{(2,172)}=99.84\right.$, Wilk's Lambda $=0.46$, $p<0.001, \eta=0.54]$ (see Fig. 2).

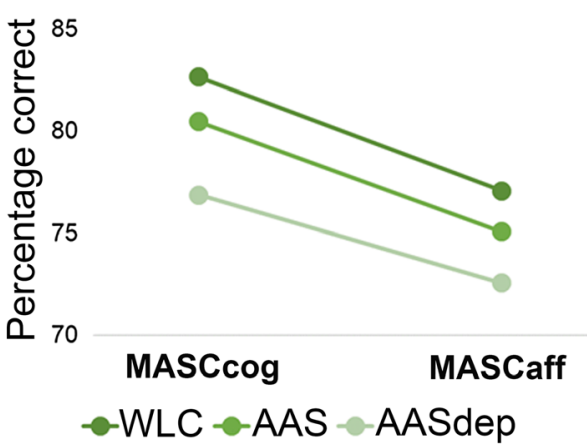

Fig. 1 Cognitive (MASCcog) and affective (MASCaff) theory of mind performance in individuals using anabolic androgenic steroids (AAS), individuals with anabolic androgenic steroid dependence (AASdep), and in weightlifting control participants (WLC)

No other interaction effects in any of the analyses were significant, see Table 3 for all results.

In the follow-up analysis controlling for the effect of drug use, the main effect of group on MASCtot remained significant $\left[F_{(6,157)}=4.29, p=0.015, \eta=0.05\right]$. It did not when IQ was controlled for $\left[F_{(6,178)}=2.78, p=0.065, \eta=0.03\right]$. The second follow-up analysis, of AAS users only, found no significant effect of being on or off cycle $\left[F_{(3,83)}=0.25, p=\right.$ $0.616, y=0.01]$.

\section{Discussion}

This study investigated the ToM abilities of males and females involved in heavy weightlifting who either did not use, who used, or who were dependent upon anabolic androgenic steroids. We found no sex differences, but a consistent pattern of group differences emerged. The AAS dependent group presented with worse performance than the other two groups, and significantly worse than the WLC group. The non-dependent AAS group had an intermediate performance between the other two groups but did not differ significantly from either. The same pattern was seen for the overall score, as for type of

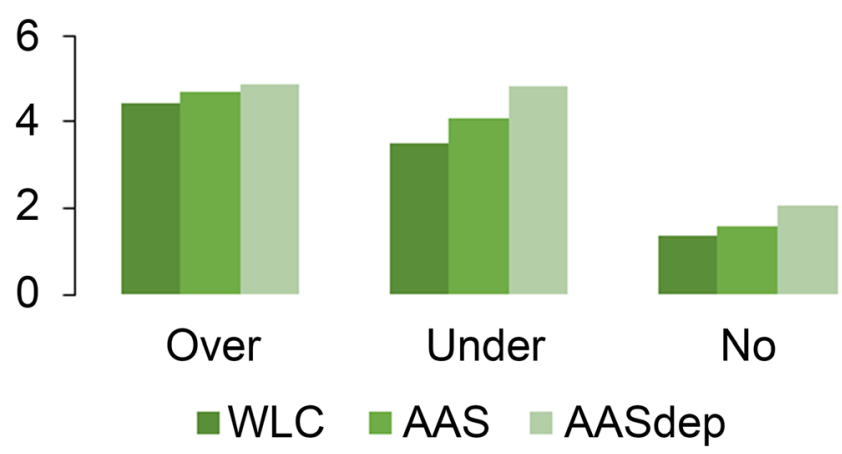

Fig. 2 Number of overmentalizing, undermentalizing, and no mentalizing errors in individuals using anabolic androgenic steroids (AAS), individuals with anabolic androgenic steroid dependence (AASdep), and in weightlifting control participants (WLC) 
Table 3 Theory of mind performance in individuals using anabolic androgenic steroids (AAS), individuals with anabolic androgenic steroid dependence (AASdep), and in weightlifting control participants (WLC)

\begin{tabular}{|c|c|c|c|c|c|c|c|}
\hline & \multicolumn{2}{|l|}{$\begin{array}{l}\text { WLC } \\
(n=85)\end{array}$} & \multicolumn{2}{|l|}{$\begin{array}{l}\text { AAS } \\
(n=43)\end{array}$} & \multicolumn{2}{|l|}{$\begin{array}{l}\text { AASdep } \\
(n=51)\end{array}$} & \multirow[t]{2}{*}{ Statistics } \\
\hline & $\begin{array}{l}\text { Females } \\
n=16 \\
\text { Mean (SD) }\end{array}$ & $\begin{array}{l}\text { Males } \\
n=69 \\
\text { Mean (SD) }\end{array}$ & $\begin{array}{l}\text { Females } \\
n=9 \\
\text { Mean (SD) }\end{array}$ & $\begin{array}{l}\text { Males } \\
n=34 \\
\text { Mean (SD) }\end{array}$ & $\begin{array}{l}\text { Females } \\
n=7 \\
\text { Mean (SD) }\end{array}$ & $\begin{array}{l}\text { Males } \\
n=44 \\
\text { Mean (SD) }\end{array}$ & \\
\hline $\begin{array}{l}\text { Total ToM } \\
\text { Range } 0-45\end{array}$ & $36.9(1.8)$ & $35.4(3.0)$ & $34.1(2.9)$ & $34.7(3.7)$ & $32.9(6.4)$ & $33.3(5.2)$ & $\begin{array}{l}\text { Group: } F=5.6, p=0.004 \eta=0.06 \\
\text { Sex: } F<0.1, p=0.839 \\
\eta=0.00 \\
\text { Gx S: } F=0.9, p=0.430 \\
\eta=0.01\end{array}$ \\
\hline Cognitive ToM & $22.1(1.5)$ & $21.4(2.1)$ & $20.8(2.3)$ & $21.0(2.3)$ & $19.6(4.0)$ & $20.1(3.4)$ & Group: $F=5.2, p=0.007$ \\
\hline Range $0-26$ & $88 \%$ & $82.3 \%$ & $80 \%$ & $80.8 \%$ & $75.4 \%$ & $77.3 \%$ & $\eta=0.06$ \\
\hline Affective ToM & $14.4(2.0)$ & $13.8(1.8)$ & $13.7(1.4)$ & $13.5(2.1)$ & $13.1(2.4)$ & $13.1(2.2)$ & Sex: $F=0.2, p=0.645$ \\
\hline Range $0-18$ & $80 \%$ & $76.7 \%$ & $76.1 \%$ & $75 \%$ & $72.8 \%$ & $72.8 \%$ & $\begin{array}{l}y=0.00 \\
\mathrm{G} \times \mathrm{S}: F=0.6, p=0.538 \\
y=0.00\end{array}$ \\
\hline $\begin{array}{l}\text { Overmentalizing errors } \\
\text { Range } 0-45\end{array}$ & $3.3(1.5)$ & $4.7(2.6)$ & $5.0(3.4)$ & $4.6(2.9)$ & $5.0(5.5)$ & $4.8(2.5)$ & $\begin{array}{l}\text { Group: } F=5.5, p=0.005 \\
\eta=0.06\end{array}$ \\
\hline $\begin{array}{l}\text { Undermentalizing errors } \\
\text { Range } 0-45\end{array}$ & $3.6(1.4)$ & $3.5(1.9)$ & $4.0(1.6)$ & $4.1(2.4)$ & $4.9(1.9)$ & $4.8(2.7)$ & $\begin{array}{l}\text { Sex: } F=0.1, p=0.762 \\
\eta=0.00\end{array}$ \\
\hline $\begin{array}{l}\text { No mentalizing errors } \\
\text { Range } 0-45\end{array}$ & $1.3(1.3)$ & $1.4(1.2)$ & $1.7(1.0)$ & $1.6(1.3)$ & $2.3(1.1)$ & $2.1(1.6)$ & $\begin{array}{l}\mathrm{G} \times \mathrm{S}: F=0.8, p=0.470 \\
\eta=0.00\end{array}$ \\
\hline
\end{tabular}

Entries in italics means that a result is statistically significant

ToM (cognitive versus affective ToM) and for ToM errors (mentalizing styles). In other words, regardless of how ToM was assessed, individuals who were dependent on AAS performed worse.

Significant main effects were present for type of ToM (cognitive versus affective ToM) as well as for ToM error types. The significant main effect of type of ToM indicates that one type of ToM is easier to understand. Figure 1 shows the cognitive and affective ToM scores of the three groups, in percentage correct. MASCcog scores are better than MASCaff scores, for all three groups, suggesting that it is easier to understand others' cognitions than their emotions, at least when using this test. Similarly, the significant main effect of ToM error types suggests that some errors are committed more often than others. The error scores of the three groups are depicted in Fig. 2; no mentalizing errors are fewer than the two other error types, regardless of group membership. These two significant main effects, yielded in two separate repeated measures ANOVAs, were not accompanied by significant interaction effects with group. This means that all three groups had a harder time understanding affective ToM than cognitive $\mathrm{ToM}$, and that none of the groups committed a specific type of error more than the other two groups did.

The group difference for the MASC total score remained significant after controlling for levels of drug use, but not after controlling for IQ. This suggests that differences in our study variables may be explained by IQ, and that the group difference in ToM abilities is simply due to differences in IQ across the three groups. Studies that report significant associations between ToM and IQ can be taken as support for such an interpretation. In our sample, explorative correlational analyses showed that the association between MASCtot and IQ corresponded to a moderate-sized correlation coefficient (Spearman's $r h o=0.36$ ). It was larger in the AAS (Spearman's rho $=0.56$ ) compared with the AASdep (Spearman's $r h o=0.30$ ) and the WLC (Spearman's $r h o=$ $0.18)$ samples. However, not only did the size of these correlation coefficients differ, ranging from small-medium to large, but also the association was not particularly strong in the group with the lowest IQ and worst ToM performance, the AASdep group. So, whereas it is a possibility that lower IQ may predispose individuals to AAS dependence as well as ToM impairment, these correlation coefficients imply that the poorer ToM abilities of the AASdep group cannot be reduced to their lower IQ. The effect of group on MASCtot after controlling for IQ $(p=0.065, \eta=0.03)$ aligns with this. It was not significant, but it approached trend-level significance. Moreover, a recent study that used the exact same tests in another clinical population suggests that impaired ToM is not redundant with IQ. In a sample of individuals with schizophrenia, WASI IQ was significantly associated with MASCtot (Spearman's $r h o=0.35$ ) but did not provide a unique contribution when entered in a regression analysis (Sjølie et al. 2020). It therefore seems likely that our AASdep group indeed has selective ToM impairments, in addition to lower IQ. Importantly, "controlling" for group differences in potential covariates is not always appropriate 
(Miller and Chapman 2001). We believe that the identified group difference in ToM detected in this study has value in itself, providing meaningful information not conveyed by the diverging intellectual level of our three participant groups.

Interestingly, none of the analyses indicated that females differ from males. Admittedly, our study is underpowered with for instance only 7 females included in the AASdep group. However, exploratory follow-up analyses, conducted separately in each sex, confirmed significant group differences for MASC total in both males $\left[F_{(2,144)}=3.97, p=0.021, \eta=\right.$ $0.05]$ and females $\left[F_{(2,29)}=3.75, p=0.036, \eta=0.21\right]$. Inspection of numerical values in Table 3 also supports the finding of no sex differences. One reason for the lack of statistical power is the relatively low number of females involved in weightlifting and use of AAS. Although AAS use is less common among females, there is historical evidence of its massive use, sometimes forced, in international sports. In the former German Democratic Republic (GDR), the administration of AAS to athletes was highly organized, overseen from the very top, and part of a political strive for success. Female athletes were certainly not spared, and sometimes received doses far exceeding what their male counterparts in the same sport were given (Franke and Berendonk 1997). Among side effects reported in GDR female athletes from this epoch were virilization (masculinized voice and facial features), hirsutism (excessive hair growth where hair does not normally grow such as outside pubic area towards navel/on thighs or in the face), and increased libido (Franke and Berendonk 1997). Less is known about cognitive side effects, but one hypothesis could be that females exposed to large amounts of AAS over time would experience a masculinizing effect on social cognition as well. Since it is often claimed that females have better social cognition than males, and there is empirical data in support of this position (Thompson and Voyer 2014), the lack of sex differences in our study could be taken to support such a hypothesis. However, as is the case for emotion recognition, identified sex differences in social cognition are often small and moderated by other factors (Thompson and Voyer 2014) or not present at all (Di Tella et al. 2020). Although there are studies that do report sex differences (Baron-Cohen et al. 2015), for ToM, the evidence of sex differences is even more limited (Turkstra et al. 2020), and an earlier study, using the exact same ToM measure, the MASC test, reported no sex differences for schizophrenia (Fretland et al. 2015). In spite of this, the public opinion is often that females are better mindreaders than males. One explanation for the lack of sex differences in the present study is that female weightlifters, regardless of whether they (ab)use AAS or not, do not have the alleged female advantage in the domain of social cognition. Whereas this is possible, it is perhaps just as likely that there are no sex differences in ToM, at least not when assessed with the MASC. In either case, the lack of significant sex and sex $\mathrm{x}$ group interaction effects may suggest that AAS do not exert any sex-specific effects on ToM, but clearly, more and larger studies are needed in order to fully answer this question.

There were no significant differences in ToM performance between AAS users who were currently on (on cycle: 43 participants) or off (off cycle: 40 participants) AAS. Whereas this may imply that levels of AAS are not of substantial importance to ToM, our study design does not allow for a sophisticated analysis of the association between ToM and specifics of AAS use. Longitudinal studies that administer ToM measures before, during, and after periods of AAS use would be better suited to answer such research questions.

When evaluating the level of social cognitive performance, it is necessary to move beyond comparisons with other weightlifters. It may be that the performance of our WLCs differs from those of healthy normal control participants or normative data. Unfortunately, such a group was not included in the current study. However, the performance of our WLC group (mean MASCtot: males $=35.4$, WLC females $=36.9$ ) was very similar to the performance of healthy controls (mean MASCtot $=35.1$ ) in another Norwegian study (Vaskinn et al. 2018). This means that our AASdep sample has ToM impairments also when compared with non-weightlifting healthy controls.

The cross-sectional nature of this study renders us unable to provide evidence for any causal explanations for the reduced ToM seen in those dependent upon AAS. We would, however, like to suggest some possible explanations. The first is that the reduced ability to infer the mental state of others is related to long-term high-dose AAS use/dependence. A gradual alteration of the neuroendocrine and central nervous system may take place with prolonged AAS use, with negative effects on ToM abilities. The fact that AAS users without dependence had an intermediate performance between non-using weightlifters and dependent AAS users is in line with this explanation, as are previous reports stating that pronounced adverse effects of AAS are foremost seen after long-term exposure and in dependence (Copeland et al. 2000; Kanayama et al. 2009b). Another explanation is that a vulnerability for developing substance use disorder co-exists with premorbidly lower social cognition in the AASdep group.

Our study has several limitations. We have mentioned the cross-sectional design and the lack of a non-weightlifting healthy control group. In addition, the number of female participants is much lower than the number for male participants. Although there are obvious reasons for this, ideally, at least scientifically speaking, we would have wished for a larger female sample. Furthermore, exact measurements of testosterone levels were not available. How current testosterone levels relate to ToM is therefore unknown. Moreover, we acknowledge that factors that we have not assessed, for example, childhood experiences and other clinical variables, may be of relevance to the association between AAS use and ToM. 
In summary, we found that male and female weightlifters who were dependent on AAS had reduced ToM abilities compared with non-using weightlifters. The reduced ToM may be among the factors underlying the higher rates of antisocial behavior reported in this population.

Funding information Open Access funding provided by University of Oslo (incl Oslo University Hospital). This work was supported by the South-Eastern Norway Regional Health Authority (grants \# 2013087, \# 2016049, \# 2017025, \# 2018075 to AB and grant \# 2017069 to AV).

\section{Compliance with ethical standards}

Prior to participation, all participants received a brochure with a description of the study, and written informed consent was collected. The study was conducted in accordance with the Declaration of Helsinki and received ethical approval from the Regional Committee for Medical and Health Research Ethics in South-Eastern Norway (2013/601).

Conflict of interest The authors declare that they have no conflict of interest.

Open Access This article is licensed under a Creative Commons Attribution 4.0 International License, which permits use, sharing, adaptation, distribution and reproduction in any medium or format, as long as you give appropriate credit to the original author(s) and the source, provide a link to the Creative Commons licence, and indicate if changes were made. The images or other third party material in this article are included in the article's Creative Commons licence, unless indicated otherwise in a credit line to the material. If material is not included in the article's Creative Commons licence and your intended use is not permitted by statutory regulation or exceeds the permitted use, you will need to obtain permission directly from the copyright holder. To view a copy of this licence, visit http://creativecommons.org/licenses/by/4.0/.

\section{References}

Achenbach TM, Rescorla LA (2003) Manual for the ASEBA adult forms and profiles. University of Vermont Research Center for Children, Youth and Families, Burlington

Baggish AL, Weiner RB, Kanayama G, Hudson JI, Lu MT, Hoffmann U, Pope HG Jr (2017) Cardiovascular toxicity of illicit anabolicandrogenic steroid use. Circulation 135:1991-2002. https://doi. org/10.1161/circulationaha.116.026945

Baron-Cohen S, Bowen DC, Holt RJ, Allison C, Auyeung B, Lombardo MV, Smith P, Lai MC (2015) The "Reading the Mind in the Eyes" test: complete absence of typical sex differences in $\sim 400$ men and women with autism. PLoS One 10(8):e0136521. https://doi.org/10. 1371/journal.pone. 0136521

Beaver KM, Vaughn MG, Delisi M, Wright JP (2008) Anabolicandrogenic steroid use and involvement in violent behavior in a nationally representative sample of young adult males in the United States. Am J Public Health 98:2185-2187. https://doi.org/ 10.2105/AJPH.2008.137018

Beery AK (2015) Antisocial oxytocin: complex effects on social behavior. Curr Opin Behav Sci 6:174-182. https://doi.org/10.1016/j. cobeha.2015.11.006

Bjørnebekk A, Westlye LT, Walhovd KB, Jørstad ML, Sundseth OO, Fjell AM (2019) Cognitive performance and structural brain correlates in long-term anabolic-androgenic steroid exposed and nonexposed weightlifters. Neuropsychology 33:547-559. https:// doi.org/10.1037/neu0000537

Bora E, Zorlu N (2017) Social cognition in alcohol use disorders: a metaanalysis. Addiction 112:40-48. https://doi.org/10.1111/add.13486

Bos PA, Terburg D, van Honk J (2010) Testosterone decreases trust in socially naïve humans. Proc National Ac Sci 107:9991-9995. https://doi.org/10.1073/pnas.0911700107

Brower (2002) Anabolic steroid abuse and dependence. Curr Psychiatry Rep 4:377-387

Brüne M, Brüne-Cohrs U (2006) Theory of mind - evolution, ontogeny, brain mechanisms and psychopathology. Neurosci Biobehav Rev 30:437-455. https://doi.org/10.1016/j.neubiorev.2005.08.001

Chapman E, Baron-Cohen S, Auyeung B, Knickmeyer R, Taylor K, Hackett G (2006) Fetal testosterone and empathy: evidence from the empathy quotient (EQ) and the "Reading the Mind in the Eyes" test. Soc Neurosci 1:135-148. https://doi.org/10.1080/ 17470910600992239

Copeland J, Peters R, Dillon P (1998) A study of 100 anabolicandrogenic steroid users. Med J Aust 168:311-312

Copeland J, Peters R, Dillon P (2000) Anabolic-androgenic steroid use disorders among a sample of Australian competitive and recreational users. Drug Alcohol Depend 60(91):96

de Souza GL, Hallak J (2011) Anabolic steroids and male infertility: a comprehensive review. BJU Int 108:1860-1865

Di Tella M, Miti F, Ardito RB, Adenzato M (2020) Social cognition and sex: are men and women really different? Personal Individ Differ 162:110045. https://doi.org/10.1016/j.paid.2020.110045

Dziobek I, Fleck S, Kalbe E, Rogers K, Hassenstab J, Brand M (2006) Introducing MASC: a movie for the assessment of social cognition. J Autism Dev Disord 36:623-636. https://doi.org/10.1007/s10803006-0107-0

Eisenegger C, Haushofer J, Feh E (2011) The role of testosterone in social interaction. Trends Cogn Sci 15:263-271

Far HRM, Ågren G, Thiblin I (2012) Cardiac hypertrophy in deceased users of anabolic androgenic stereoids: an investigation of autopsy findings. Cardiovasc Pathol 21:312-316. https://doi.org/10.1016/j. carpath.2011.10.002

Fett AKJ, Viechtbauer W, Dominguez MD, Penn DL, van Os J, Krabbendam L (2011) The relationship between neurocognition and social cognition with functional outcomes in schizophrenia: a meta-analysis. Neurosci Biobehav Rev 35:573-588. https://doi.org/ 10.1016/j.neubiorev.2010.07.001

First MB, Spitzer RL, Gibbon M, Williams JBW (1996) Structured clinical interview for DSM-IV axis I disorders, Clinical Trials Version (SCID-CV). American Psychiatric Press, Washington, DC

Franke WW, Berendonk B (1997) Hormonal doping and andrenogenization of athletes: a secret program of the German Democratic Republic government. Clin Chem 43:1262-1279

Fretland RA, Andersson S, Sundet K, Andreassen OA, Melle I, Vaskinn A (2015) Theory of mind in schizophrenia: error types and associations with symptoms. Schizophr Res 162:42-46. https://doi.org/10. 1016/j.schres.2015.01.024

Green MF, Penn DL, Bentall R, Carpenter WT, Gaebel W, Gur RC, Kring AM, Park S, Silverstein SM, Heinssen R (2008) Social cognition in schizophrenia: an NIMH workshop on definitions, assessment, and research opportunities. Schizophr Bull 34:1211-1220. https://doi.org/10.1093/schbul/sbm145

Gruber AJ, Pope HG Jr (2000) Psychiatric and medical effects of anabolic-androgenic steroid use in women. Psychother Psychosom 69:19-26. https://doi.org/10.1159/000012362

Halversen TF, Orleans-Pobee M, Merritt C, Sheeran P, Fett AK, Penn DL (2019) Pathways to functional outcomes in schizophrenia spectrum disorders: meta-analysis of social cognitive and neurocognitive predictors. Neurosci Biobehav Rev 105:212-219. https://doi.org/10. 1016/j.neubiorev.2019.07.020 
Hauger LE, Sagoe D, Vaskinn A, Arnevik EA, Leknes S, Jørstad ML, Bjørnebekk A (2019) Anabolic androgenic steroid dependence is associated with impaired emotion recognition. Psychopharmacol 236:2667-2676. https://doi.org/10.1007/s00213-019-05239-7

Hauger LE, Westlye LT, Bjørnebekk A (2020) Anabolic androgenic steroid dependence is associated with executive dysfunction. Drug Alcohol Depend 208:107874. https://doi.org/10.1016/j.drugalcdep. 2020.107874

Heffernan T, Battersby L, Bishop P, O’Neill TS (2015) Everyday memory deficits associated with anabolic-androgenic steroid use in regular gymnasium users. Open Psychiatry J 9:1-6. https://doi.org/10. 2174/1874354401509010001

Hermans EJ, Putman P, van Honk J (2006) Testosterone administration reduces empathetic behavior: a facial mimicry study. Psychoneuroendoccrinology 31:859-866

Kanayama G, Hudson JI, Pope HG (2008) Long-term psychiatric and medical consequences of anabolic-androgenic steroid abuse: a looming public health concern? Drug Alcohol Depend 98:1-12

Kanayama G, Brower KJ, Wood RI, Hudson JI, Pope HG Jr (2009a) Anabolic-androgenic steroid dependence: an emerging disorder. Addiction 104:966-1978. https://doi.org/10.1111/j.1360-0443. 2009.02734.x

Kanayama G, Hudson JI, Pope HG (2009b) Features of men with anabolic-androgenic steroid dependence: a comparison with nondependent AAS users and with AAS nonusers. Drug Alcohol Depend 102:130-137

Kanayama G, Brower KJ, Wood RI, Hudson JI, Pope HG Jr (2009c) Issues for DSM-V: clarifying the diagnostic criteria for anabolic androgenic steroid dependence. Am J Psychiatry 166:642-645. https://doi.org/10.1176/appi.ajp.2009.08111699

Kanayama G, Kean J, Hudson JI, Pope HG Jr (2013) Cognitive deficits in long-term anabolic-androgenic steroid users. Drug Alcohol Depend 130:208-214. https://doi.org/10.1016/j.drugalcdep.2012.11.008

Khorashad BS, Khazai B, Roshan GM, Hiradfar M, Afkhamizadeh M, van de Grift TC (2018) Prenatal testosterone and ToM development: findings from disorders of sex development. Psychoneuroendocrinology 89:250-255. https://doi.org/10.1016/j. psyneuen.2017.12.008

Macdonald K, Macdonald TM (2010) The peptide that binds: a systematic review of oxytocin and its prosocial effects in humans. Harv Rev Psychiatry 18:1-21. https://doi.org/10.3109/ 10673220903523615

Miller GA, Chapman JP (2001) Misunderstanding analysis of covariance. J Abnorm Psychol 110:40-48

Montoya ER, Terburg D, Bos PA, van Honk J (2012) Testosterone, cortisol, and serotonin as key regulators of social aggression: a review and theoretical perspective. Motiv Emot 36:65-73

Oberlander JG, Henderson LP (2012) The Sturm und Drang of anabolic steroid use: angst, anxiety, and aggression. Trends Neurosci 35: 382-392

Ochsner KN (2008) The social-emotional processing stream: five core constructs and their translational potential for schizophrenia and beyond. Biol Psychiatry 64:48-61. https://doi.org/10.1016/j. biopsych.2008.04.024

Oskui PM, French WJ, Herring MJ, Mayeda GS, Burstein S, Kloner RE (2013) Testosterone and the cardiovascular system: a comprehensive review of the clinical literature. J Am Heart Assoc 2:e000272. https://doi.org/10.1161/JAHA.113.000272

Parkinson AB, Evans NA (2006) Anabolic androgenic stereoids: a survey of 500 users. Med Sci Sports Exerc 38:644-651. https://doi.org/10. 1249/01.mss.0000210194.56834.5d

Pinkham (2014) Social cognition in schizophrenia. J Clin Psych 75(suppl2):14-19. https://doi.org/10.4088/JCP.13065su1.04
Pope HG Jr, Katz DL (1994) Psychiatric and medical effects of anabolicandrogenic steroid use. A controlled study of 160 athletes. Arch Gen Psychiatry 51:375-382. https://doi.org/10.1001/archpsyc.1994. 03950050035004

Pope HG, Kean J, Nash A, Kanayama G, Samuel DB, Bickel WK, Hudson JI (2010) A diagnostic interview module for anabolicandrogenic steroid dependence: preliminary evidence of reliability and validity. Exp Clin Psychopharmacol 18:203-213. https://doi. org/10.1037/a0019370

Preller KH, Hulka LM, Vonmoos M, Jenni D, Baumgartner MR, Seifritz E, Dziobek I, Quednow BB (2014) Impaired emotional empathy and related social network deficits in cocaine users. Addict Biol 19:452-466. https://doi.org/10.1111/adb.12070

Rasmussen JR, Schou M, Madsen PL, Selmer C, Johansen ML, Ulriksen PS, Dreyer T, Kümler T, Plesner LL, Faber J, Gustafsson F, Kistorp C (2018) Cardiac systolic dysfunction in past illicit users of anabolic androgenic steroids. Am Heart J 203:49-56. https://doi.org/10. 1016/j.ahj.2018.06.010

Sagoe D, Molde H, Andreassen CS, Torsheim T, Pallesen S (2014) The global epidemiology of anabolic-androgenic steroid use: a metaanalysis and meta-aggression analysis. Ann Epidemiol 24:383398. https://doi.org/10.1016/j.annepidem.2014.01.009

Sanvicente-Vieira B, Romani-Sponchiado A, Kluwe-Schiavon B, Brietzke E, Araujo RB, Grassi-Oliveira R (2017) Theory of mind in substance users: a systematic mini-review. Subst Use Misuse 52: 127-133. https://doi.org/10.1080/10826084.2016.1212890

Sjølie C, Meyn EK, Raudeberg R, Andreassen OA, Vaskinn A (2020) Nonsocial cognitive underpinnings of theory of mind in schizophrenia. Psychiatry Res 289:113055

Thompson AE, Voyer D (2014) Sex differences in the ability to recognise non-verbal displays of emotion: a meta-analysis. Cognit Emot 28: 1164-1195

Turkstra LS, Mutlu B, Ryan CW, Despins Stafslien EH, Richmond EK, Hosokawa E, Duff MC (2020) Sex and gender differences in emotion recognition and theory of mind after TBI: a narrative review and directions for future research. Front Neurol 11:59. https://doi.org/10. 3389/fneur.2020.00059

van Honk J, Terburg D, Bos PA (2011a) Further notes on testosterone as a social hormone. Trends Cogn Sci 15:291-292. https://doi.org/10. 1016/j.tics.2011.05.003

van Honk J, Schutter DJ, Bos PA, Kruijt AW, Lentjes EG, Baron-Cohen S (2011b) Testosterone administration impairs cognitive empathy in women depending on second-to-fourth digit ratio. Proc Natl Acad Sci U S A 108:3448-3452. https://doi.org/10.1073/pnas. 1011891108

Vaskinn A, Andersson S, Østefjells T, Andreassen OA, Sundet K (2018) Emotion perception, non-social cognition and symptoms as predictors of theory of mind in schizophrenia. Compr Psychiatry 85:1-7. https://doi.org/10.1016/j.comppsych.2018.05.002

Vlad M, Raucher-Chéné D, Henry A, Kaladjian A (2018) Functional outcome and social cognition in bipolar disorder: is there a connection? Eur Psychiatry 52:116-125. https://doi.org/10.1016/j.eurpsy. 2018.05.002

Wechsler D (2007) Wechsler abbreviated scale of intelligence. Norwegian manual supplement. Stockholm: Pearson Assessment

Yates WR, Perry P, Murray S (1992) Aggression and hostility in anabolic stereoid users. Biol Psychiatry 31:1232-1234. https://doi.org/10. 1016/0006-3223(92)90344-y

Publisher's note Springer Nature remains neutral with regard to jurisdictional claims in published maps and institutional affiliations. 